\title{
Operationalization of COVID-19 Rapid Diagnosis Using Xpert@ Xpress SARS CoV-2 Assay in Resource-Limited Settings: Early Implementation Lessons From Uganda
}

Andrew Nsawotebba ( $\sim$ andrewtebba@gmail.com )

National Health Laboratory Service https://orcid.org/0000-0002-5452-3603

Ivan Ibanda

National Health Laboratory Services

Isaac Ssewanyana

National Health Laboratory Services

Bernard Ssentalo Bagaya

Makerere University College of Health Sciences

Abdunoor Nyombi

National Tuberculosis Reference Laboratory/Supranational Reference Laboratory

Atek Kagirita

Republic of Uganda Ministry of Health

Dennis Mujuni

Marascientific Uganda

Didas Tugumisirize

National Tuberculosis and Leprosy Control Division

Robert Kaos Majwala

National Tuberculosis and Leprosy Control Division

Francis Ocen

Africa Centres for Disease Control and Prevention/African Society for Laboratory Medicine

Joel Kabugo

National Tuberculosis Reference Laboratory/Supranational Reference Laboratory

Isa Adam

National Tuberculosis Reference Laboratory/Supranational Reference Laboratory

Enock Wekiya

National Tuberculosis Reference Laboratory/Supranational Reference Laboratory

Benoni Munduku

National Health Laboratory Services

Lillian Linda

National Health Laboratory Services 


\section{Morgan Otita}

Makerere University Infectious Diseases Institute

\section{Simon Kalyesubula-Kibuuka}

National Health Laboratory Services

\section{Christopher Okiira}

National Health Laboratory Services

\section{Edgar Kigozi}

Makerere University College of Health Sciences

\section{Patrick Ogwok}

National Health Laboratory Services

\section{Moses Lutakoome Joloba}

Makerere University College of Health Sciences

\section{Susan Nabadda}

National Health Laboratory Services

\section{Willy Ssengooba}

Makerere University Lung Institute, Makerere University College of Health Sciences

\section{Research}

Keywords: COVID-19, Xpert® Xpress SARS CoV-2, Rapid diagnosis, Resource-Limited Settings, Implementation

Posted Date: January 29th, 2021

DOI: https://doi.org/10.21203/rs.3.rs-154102/v1

License: (c) (1) This work is licensed under a Creative Commons Attribution 4.0 International License. Read Full License 


\section{Abstract}

Introduction: The novel Severe Acute Respiratory Syndrome Coronavirus 2 (SARS-CoV-2) that causes COVID-19 disease is a global challenge. Several countries have adopted testing, isolation, and tracing strategy towards the control of the COVID-19 pandemic, but access to rapid and accurate testing is still a global challenge. The conventional PCR - based assay is the most commonly used test yet it has huge costs, infrastructural, and procurement logistical challenges. The Xpert® Xpress SARS-CoV-2 test is an automated in - vitro diagnostic test for the qualitative detection of nucleic acid from SARS-CoV-2 within a turnaround time of 60 minutes on the widely used GeneXpert Dx Instrument Systems. Here we document the best practices and challenges encountered with the operationalization of Xpert ${ }^{\circledR}$ Xpress SARS-CoV-2 testing in a resource-limited setting.

Materials and Methods: The Xpert ${ }^{\circledR}$ Xpress SARS-CoV-2 implementation followed an operational work plan that included; Laboratory COVID-19 policy and planning, situational analysis of the Laboratory network, country Xpert ${ }^{\circledR}$ Xpress SARS-CoV-2 assay verification, and rollout at Mutukula Port Health Laboratory. The Laboratory strategy was based on a set of six objectives; conducting infrastructural modifications, building a strong COVID-19 testing capacity, developing robust Laboratory Quality and Information Management Systems, establishing a Bio-risk management and Bio-banking capacity.

Results: The Xpert ${ }^{\circledR}$ Xpress SARS-CoV-2 testing implementation team that was appointed by the Ministry of Health (Uganda) successfully established the Xpert® Xpress SARS-CoV-2 testing Laboratory at Mutukula border in Uganda. As of $9^{\text {th }}$ July 2020 , this Laboratory had tested a total of 10,990 samples with a median turnaround time of 75 (IQR: 60 - 75) minutes for samples of persons entering through Mutukula Land Point of Entry as compared to the median TAT 1980 minutes before it was established. The laboratory had only one discordant result out of 20 panels in the inter-laboratory comparison retesting program.

Conclusions: Implementation of Xpert $\circledast$ Xpress SARS-CoV-2 testing for rapid diagnosis of COVID-19 is feasible and significantly reduces the long TAT observed with conventional RT-PCR based testing. The operationalization of the Xpert ${ }^{\circledR}$ Xpress SARS-CoV-2 testing is largely dependent on the initial planning, adequacy of resources, and preparedness within the laboratory network. Challenges include; the difference in approaches to COVID-19 response, the attitude of truck-drivers/persons on Infection Prevention and Control measures, language barrier, and waste management issues.

\section{Introduction}

In December 2019, numerous cases of mysterious pneumonia with unknown etiology occurred in Wuhan, Hubei Province, China $[1,2,3]$. This pneumonia quickly spread to other provinces of China and abroad. On the $7^{\text {th }}$ of January 2020 , a new coronavirus was identified in the human throat swab sample by the Chinese Center for Disease Control and Prevention (CDC) and was consequently named as 2019 Novel CoronaVirus (2019nCoV) by the World Health Organization (WHO) [1, 2]. Upon worsening of the situation, 
the WHO declared the outbreak as the public health emergency of international concern (PHEIC) on January 31,2020 [4]. On $11^{\text {th }}$ February 2020, the virus was rechristened as Severe Acute Respiratory Syndrome Corona Virus-2 (SARS-CoV-2) by the International Committee on Taxonomy of Viruses [5], and WHO subsequently declared the epidemic disease caused by SARS-CoV-2 as Coronavirus Disease 2019 (COVID-19) [6]. The clinical features of COVID-19 are diverse, ranging from an asymptomatic state to acute respiratory distress syndrome and multi-organ dysfunction [7]. The frequent clinical features comprise fever, cough, sore throat, headache, fatigue, headache, myalgia and breathlessness [7], and conjunctivitis has also been described. Thus, they are indistinguishable from other respiratory infections [7]. As of June $21^{\text {st, }} 2020$, COVID-19 had continued to spread worldwide, causing over 8.914 million cases and over 466 thousand deaths [6]. The European region is the most affected with more than $50 \%$ of cases and $60 \%$ of deaths reported [8]. The United States of America has the highest number of cases globally (695,350 cases) and the highest number of confirmed deaths (32,427 deaths) [9]. The African

region is the least affected with 13,892 cases and 628 deaths, but the numbers are increasing [9]. Uganda has so far confirmed $>340$ cases of COVID-19 as of $30^{\text {th }}$ May 2020 , and no related deaths $[9,10]$. Generally, the mortality rates for cases globally remain between $1 \%$ and $2 \%$ [11]. From the onset of this public health crisis, the need for rapid and accurate laboratory testing was highlighted, and researchers responded by developing the first diagnostic tests for COVID-19 within days of the release of the viral genome sequence (12).

\section{Strategies to contain the disease}

There are advances towards the development of effective vaccines and drugs [13]. However, these may delay to reach the mass population, and so till then adopting appropriate prevention and control is the best option to contain the SARS-CoV-2 pandemic [13]. Perhaps the most important insight from the international COVID-19 response to date has been that to successfully slow transmission and safeguard health systems, it is essential to accurately diagnose and effectively isolate and care for all cases of COVID-19 including those with the mild or moderate disease either in health or home settings, depending on the context and degree of illness [14]. To enhance the above strategy, the primary focus of most countries has been the rapid identification, testing, and treatment of patients with serious and severe COVID-19, and the sheltering of individuals at the highest risk of unfortunate consequences through tracing, quarantining, and supporting contacts [14].

\section{Diagnosis of COVID-19 and the Xpert@ Xpress SARS-CoV-2 PCR assay}

COVID-19 diagnosis relies on a combination of clinical symptoms with or without radiological imaging, and confirmed by molecular techniques such as SARS-CoV-2 PCR [6]. However, it is worth noting that the major diagnostic tool employed globally as observed from various published literature for the diagnosis of the SARS-CoV-2 has been the Real-Time Polymerase Chain Reaction (PCR) Nucleic Acid-based test [7, 15]. Currently, either a Real-Time Polymerase Chain Reaction (RT-PCR) targeting the envelope (E gene) in combination with polymerase (RdRP-gene) is being used as described [16] or targeting the nucleoprotein (N-gene) as recommended by the US Centers for Disease Control and Prevention [17]. However, numerous 
bottlenecks have been stated since its implementation. From a technical point of view, the process is time-consuming with sample RNA extraction and PCR run-time of approximately 6 hours and a turnaround time of 12-24 hours. Since providing fast results is of critical importance to stop the pandemic through ensuring timely and adequate treatment of patients, developing high-quality rapid point of care diagnostics is essential. Among the most known Point of Care (POC) tests include the antigen-based and the molecular-based tests. The antigen-based tests have the potential in providing quick diagnosis however; these have demonstrated low sensitivity with the implication of high rates of false negatives thus unreliable to use [6].

The novel molecular point of care test, Xpert® Xpress SARS-CoV-2 FDA-approved assay, can significantly reduce the time taken to get a result. This helps to facilitate faster clinical decision-making $[18,19]$. The assay employed on the GeneXpert analyzer (Cepheid, Sunnyvale, CA) was launched in March upon receipt of Emergency Use Authorization from the United States Food and Drug Administration on $20^{\text {th }}$ March 2020 [8]. The assay's cartridge contains primers and probes and internal controls used in RT-PCR for the in vitro qualitative detection of SARS-CoV-2 RNA in upper respiratory specimens collected in viral transportation medium/normal saline [20]. The assay is currently among the first in class for several reasons: (i) improved sensitivity over prior attempts at using Nucleic Acid Amplification Testing (NAAT) strategies, (ii) short turnaround time (iii) a modular format allowing testing across a spectrum of volume needs, (iv) the possibility of automation (Infinity group of analyzers), (v) simplicity, (vi) speed, and (vii) Less human involvement hence less human errors. Additional advances of the technology include the cartridge designed with all relevant components ("lab-in-a-cartridge" is a term frequently used to describe the platform format) and the analyzer with its modular format. This gives random access in nature and has connectivity capabilities to various laboratory information systems and a remote connectivity platform for the monitoring of instrument performance at a central level.

\section{Adoption of the Xpert@ Xpress Sars-CoV-2 Assay in Resource-Limited Settings}

Several countries haven't yet incorporated or are planning to incorporate the Xpert $\circledast$ Xpress SARS CoV-2 assay in their national COVID-19 control and management operations as of July 2020. This evident reluctance to implement the assay even amidst FDA approval may largely be attributed to the lack of implementation models to guide the integration of the assay in the national COVID-19 control and management operations among many other limitations. Besides, there are uncertainties around field performance, overall program cost, and its impact, with no guidance on how to operationalize the assay given the dynamic nature of clinical and diagnostic algorithms that are subjected to relatively frequent reviews regularly due to the many uncertainties around this novel disease hence the purpose of this guidance.

Like many countries, SARS-CoV-2 testing in Uganda was previously limited to the centralized National Reference Laboratory using in-house PCR at the Uganda Virus Research Institute (UVRI). This has been associated with long sample transit turnaround time (TAT), low thorough-put, and arguably long results TAT. Earlier in the COVID-19 outbreak in Uganda, most of the cases were among truck drivers through the 
national transit routes in the East and Southern parts of the country, hence as a preventive measure, the National COVID-19 Task Force recommended testing for all truck drivers into the country. However, this led to long results turnaround time and general frustration among truck drivers given that these drivers were not allowed to enter the country except with negative COVID-19 test results. Testing for COVID-19 at the border was the appropriate biosecurity tool, however, the long results TAT associated with border testing meant frustration of border traffic flow and hence regional trade. Xpert ${ }^{\circledR}$ Xpress SARS-CoV-2 with a TAT of 2 hours with minimal infrastructural and biosafety requirements was one of the solutions to such a challenge. Tanzania registered her first COVID-19 case on the $16^{\text {th }}$ March; by April $30^{\text {th }}$, she had a total of 480 cases inclusive of community cases, and 16 COVID-19 related deaths which were so far the highest among East African states [22]. By that same time, Uganda had registered 83 cases with zero community cases and deaths [23].

We provide our experience on the implementation of the Xpert® Xpress SARS-CoV-2 assay for the diagnosis of COVID-19 at a Port Health Laboratory (PHL) in rural Uganda. This may be useful for countries with similar challenges that may be in the early stages of the establishment of a PHL for diagnosis of COVID-19.

\section{Materials And Methods}

\section{Health policy and planning}

This involved defining the composition, roles, and responsibilities of an Xpert® Xpress SARS CoV-2 implementation team. This team was tasked to develop the Xpert Xpress National diagnostic algorithm and guidelines and update the National Guidelines for COVID-19 testing.

\section{National Xpert@ Xpress SARS-CoV-2 Assay Verification}

This was done by the Xpert ${ }^{\circledR}$ Xpress SARS CoV-2 implementation team to provide evidence that the Xpert ${ }^{\circledR}$ Xpress SARS-CoV-2 assay could achieve the performance characteristics obtained during the manufacturer's method validation and whether the method was suitable for its intended use in the population of patients being targeted using Conventional PCR as a reference standard. Ten known positives $(n=10)$ and 20 known negatives $(n=20)$ samples were tested at the Department of Medical Microbiology, Mycobacteriology (BSL-3) laboratory, Makerere University. The agreement between the results of the Xpert ${ }^{\circledR}$ Xpress SARS-CoV-2 test and Conventional PCR was established as well as the InterOperator Reproducibility of the Xpert ${ }^{\circledR}$ Xpress SARS-CoV-2 assay. The verification activity was also used as a training exercise for the laboratory personnel. The trained laboratory personnel had two years' experience of the use of GeneXpert systems at the National Tuberculosis Reference Laboratory and some of them had been trained as "Super Users" by Cepheid.

\section{Situational analysis of the National Lab Network to identify potential Xpert@ Xpress SARS CoV-2 Laboratories}


The Xpert ${ }^{\circledR}$ Xpress SARS CoV-2 implementation team conducted a situational analysis to establish testing sites that were strategically located from a public health perspective to impactfully yield the best results. Key elements to be assessed included testing site location, infrastructure (design, adequacy of space), accommodation for staff, availability of engineering biosafety requirements, GeneXpert platforms, software versions (Dx systems) of existing GeneXpert platforms and database back-ups at the sites, water, electricity, internet, and power back-up systems and security for both personnel and GeneXpert platforms.

\section{Establishment of the Xpert $\AA^{\circledR}$ Xpress SARS-CoV-2 laboratory at Mutukula (Uganda) Land Point of Entry: from first stone to operational approval}

The first Xpert® Xpress SARS-CoV-2 Testing Laboratory in Uganda was established at Mutukula OneStop Border Post (OSBP) in May 2020. This OSBP ( $\left.1^{\circ} 00^{\prime} 00.0^{\prime \prime} S, 31^{\circ} 25^{\prime} 00.0^{\prime \prime} \mathrm{E}\right)$ has several stakeholders including the Port Health, Immigration, Customs, Uganda National Bureau of Standards, Liaison Officers, Chieftaincy of Military Intelligence, Uganda Police, Uganda People's Defence Forces, and Red Cross. Mutukula (Uganda) is located in the extreme southern Kyotera district and it is the major crossing point, for both human and commercial traffic between Uganda and Tanzania [21].

A detailed operational plan was developed to implement recommendations resulting from the situational analysis. The plan entailed improvement on the existing infrastructure to accommodate the Xpert® Xpress SARS-CoV-2 assay; risk assessment; building a strong COVID-19 sample collection and testing capacity; establishing Laboratory Quality and Information Management systems; and building of Bio-risk management capacity.

\section{a) Risk assessment for the Mutukula Xpert@ Xpress SARS CoV-2 Testing Laboratory}

WHO requires that all Public Health Laboratories conduct a local and institutional risk assessment to ensure competence to safely perform the intended testing with appropriate risk control measures in place [24]. We, therefore, conducted a Laboratory risk assessment according to the template provided in the February 2020 WHO Laboratory biosafety guidance related to coronavirus disease 2019 (COVID-19). This was done in a step by step manner from gathering information (hazard identification), evaluation of the risks, risk characterization, development of a risk control strategy, selection to development of a strategy for implementation of the identified risk control measures

\section{b) Lab design and construction of a Biosafety Level II laboratory}

WHO interim guidelines for COVID-19 laboratory biosafety, requires that non-propagative diagnostic laboratory work (for example, sequencing, nucleic acid amplification test [NAAT]) on clinical specimens from patients who are suspected or confirmed to be infected with COVID-19 should be conducted at a facility using procedures equivalent to Biosafety Level 2 (BSL-2) [24]. The pre-existing space at the Mutukula port health building was found to be ideal for the BSL2 lab. This was modified in terms of design to accommodate the necessities for handling the infectious SARS-CoV-2. 


\section{c) Laboratory equipment and materials}

The WHO interim guidelines for lab COVID-19 testing required the manipulation of samples required to be undertaken in an appropriately maintained and validated Biosafety cabinet (BSC) class II. The Gene Xpert ${ }^{\circledR}$ system is the platform required for the execution of the Xpert $\circledast$ Xpress SARS-CoV-2 assay. Refrigerators $\left(2-8^{\circ} \mathrm{C}\right)$ or cooler boxes are required for short term storage of samples while long term storage requires freezers $\left(-80\right.$ and $\left.-20^{\circ} \mathrm{C}\right)$. Appropriate disinfectants with proven activity against enveloped viruses must be availed and used for the recommended contact time, at the correct dilution and within the expiry date after the working solution is prepared.

\section{d) Human resource}

Mobilization of human resources that were acquainted with the Cepheid GeneXpert Systems. These then had to be trained and deemed competent before performing Xpert ${ }^{\circledR}$ Xpress SARS-CoV-2 testing.

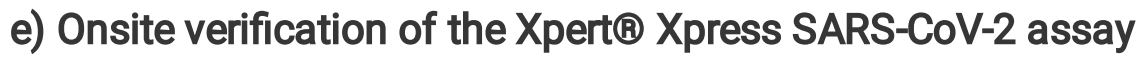

Briefly, a retesting of a total of 10 known positive and 20 known negative samples of the already tested SARS-COV-2 samples from Molecular Microbiology Laboratory, Makerere University was done at Mutukula Port Health Laboratory just as the verification process. The agreement between the results of the Xpert ${ }^{\circledR}$ Xpress SARS-CoV-2 test at Mutukula PHL and the Conventional PCR at the Makerere Microbiology laboratory was established.

\section{f) Laboratory commissioning}

To ensure that the newly established laboratory and its facilities meet the safety standards and provide a safe environment for laboratory personnel to conduct their work during the pandemic, an onsite inspection by the Ministry of Health and its partners had to be conducted.

\section{g) Implementation of Quality Assurance activities}

The Laboratory established a comprehensive and systematic Quality Assurance program to enable the achievement and maintenance of high levels of accuracy and proficiency in COVID-19 testing, to ensure the reliability and reproducibility of results and therefore inspire confidence in its customers. Activities that were implemented included assay verification, training and competence assessment, equipment maintenance, installation and validation of the Laboratory Information Management System (LIMS), lot testing, establishment and monitoring of quality indicators, and Continuous Quality Improvement (CQI) using feedback from quality audits, Customer Satisfaction Survey (CSS), and External Quality Assessment (EQA e.g. inter-laboratory comparison) responses.

Mutukula Port Health Laboratory participated in an Inter-Laboratory comparison re-testing program with Tororo COVID-19 Mobile Field-Testing Lab, which works in almost a similar environment with MPHL. Tororo Mobile Laboratory uses $200 \mu l$ primary sample, manual extraction by DAAN kit, and Altona 
protocol duo target (E and S) detection on Biorad CXF97 whereas MPHL loads 300 $\mu$ l of a primary sample for Xpert ${ }^{\circledR}$ Xpress SARS-CoV-2 assay that targets both E and N2 genes with automated extraction and detection.

\section{h) The assessment for capacity and capability to conduct COVID-19 testing}

This was conducted by WHO consultants using the WHO 2019-nCoV Laboratory Assessment tool. This tool was designed to assess ten (10) core capacities of laboratories that have implemented testing for SARS-CoV-2. These included: Organization and management; Documents; Specimen collection; Handling and transport; Data and information management; Consumables and reagents management; Equipment management; Facilities; Human resources; Bio-risk management; and Public health functions.

\section{Results}

\section{Health policy and planning}

The Ministry of Health $(\mathrm{MOH})$ delegated the responsibility for planning and implementing Xpert ${ }^{\circledR}$ Xpress SARS-CoV-2 testing activities to a team comprised of representatives from all key stakeholders, these included Uganda National Health Laboratory Services (UNHLS), National Tuberculosis Reference Laboratory (NTRL), Caroga Microhaem Ltd (Cepheid Authorized Service provider), National Medical Stores (NMS), and Mycobacteriology (BSL-3) Laboratory at the Department of Medical Microbiology of Makerere University. This team was mandated to advise $\mathrm{MOH}$ on strategies to implement Xpert® Xpress SARS-CoV-2 testing, develop action plans that could ensure all aspects of the implementation are covered, oversee the implementation of activities, and assess the impact and success of the implementation. The team drafted the National Xpert ${ }^{\circledR}$ Xpress SARS-CoV-2 diagnostic algorithm and also updated all national guidelines that refer to screening and diagnosis of COVID-19 as in Fig 1.

\section{National verification of the assay at Makerere University Mycobacteriology (BSL-3) Laboratory}

The sensitivity, specificity, positive predictive value, and negative predictive value were $100 \%$ for the Xpert® Xpress SARS-CoV-2 test against the gold standard Conventional PCR as stated in Table 1.

Table 1: A contingency table for Xpert Xpress SARS COV-2 diagnostic testing in comparison to RT-PCR 


\begin{tabular}{|c|c|c|c|c|}
\hline & \multicolumn{2}{|c|}{$\begin{array}{c}\text { Conventional RT PCR- } \\
\text { Gold Standard }\end{array}$} & \\
\hline & & Positive & Negative & \\
\hline \multirow{2}{*}{$\begin{array}{c}\text { Xpert }{ }^{\circledR} \\
\text { Xpress SARS } \\
\text { COV-2 } \\
\text { Assay }\end{array}$} & Positive & $\begin{array}{c}\text { True Positive } \\
\text { (TP) }=10\end{array}$ & $\begin{array}{c}\text { False Positive } \\
\text { (FP) }=0\end{array}$ & $\begin{array}{c}\text { Positive predictive value (PPV) } \\
\Rightarrow \quad \mathrm{TP} /(\mathrm{TP}+\mathrm{FP}) \\
100 \%\end{array}$ \\
\hline & Negative & $\begin{array}{c}\text { False Negative } \\
(F N)=0\end{array}$ & $\begin{array}{c}\text { True Negative } \\
(\mathrm{TN})=\mathbf{2 0}\end{array}$ & $\begin{array}{c}\text { Negative predictive value } \\
(\mathrm{NPV}) \\
=\mathrm{TN} /(\mathrm{FN}+\mathrm{TN}) \\
100 \%\end{array}$ \\
\hline \multirow{2}{*}{\multicolumn{2}{|c|}{ Total }} & 10 & 20 & \\
\hline & & $\begin{array}{c}\text { Sensitivity } \\
=\mathrm{TP} /(\mathrm{TP}+ \\
\mathrm{FN}) \\
100 \%\end{array}$ & $\begin{array}{c}\text { Specificity } \\
=\mathrm{TN} /(\mathrm{FP}+ \\
\mathrm{TN}) \\
100 \%\end{array}$ & \\
\hline
\end{tabular}

The Inter-Operator Reproducibility of testing using Xpert ${ }^{\circledR}$ Xpress SARS-CoV- 2 was $100 \%$ as stated in Table 2.

Table 2: The inter-operator reproducibility evaluation

\begin{tabular}{|llll|}
\hline Test result obtained & Operator $\mathbf{1}$ & Operator $\mathbf{2}$ & \% agreement \\
\hline Positive & 3 & 3 & 100 \\
Negative & 3 & 3 & 100 \\
\hline
\end{tabular}

Results of the situational analysis

This was based on a set of criteria as summarized in Table 3. Upon evaluation of the situational analysis results, the Port Health Laboratory at the Mutukula border met all the requirements that were included on the checklist.

Table 3: Situational analysis at the selected land point of entries 


\begin{tabular}{|ll|}
\hline Selection Criteria & MPHL \\
Location & Tanzania - Uganda International border \\
Design & \\
Space & Modifiable \\
Anteroom & Ample \\
Handwashing sink & Available \\
Accommodation for staff & Available \\
Engineering biosafety requirements e.g. BSC & Available \\
GeneXpert platforms & Available \\
Water & \\
Electricity & Four GXP IV and One GXP XVI \\
Internet & Available \\
Cold Storage conditions & Available \\
Power back-up systems & Not available \\
Security for both personnel and GeneXpert platforms & Available \\
& Available \\
& \\
\hline
\end{tabular}

\section{Establishment of the Mutukula Xpert $\AA^{8}$ Xpress SARS-CoV-2 laboratory at Mutukula (Uganda) Land Point of Entry: From the first stone to operational approval}

\section{Risk assessment of the laboratory}

Upon risk evaluation, the overall initial high risk was mainly due to homogenization of the sample, loading the sample into the cartridge during the Xpert® Xpress SARS-CoV-2 assay, and waste handling. The laboratory developed and implemented a risk control strategy with effective and sustainable measures including the use of a certified BSC Class II, appropriate personal protective equipment (PPE), development of administrative controls, appropriate use of disinfectants, safe housekeeping practices, timely collection and disposal of generated waste. The administrative controls included biosafety training, development of policies, procedures, bench aids, and use of signages. The residual risk was very low hence a safer working environment for personnel.

\section{Laboratory design and biosafety}


The laboratory was modified by the installation of two workbenches, an air conditioner, a hand-washing sink, and a sample reception window in consideration of the risk control strategy. The laboratory met the structural and biosafety requirements as stipulated by the WHO Laboratory Biosafety Manual, 3rd edition, for BSL-2 laboratories and WHO Laboratory biosafety guidance related to coronavirus disease 2019 (COVID-19) as elaborated in Tables 1 and 2.

Table 4: The biosafety guidelines for BSL2 according to the WHO biosafety manual $3^{\text {rd }}$ edition and its Laboratory guidelines for COVID-19 testing

\begin{tabular}{|c|c|c|c|}
\hline Biosafety item & $\begin{array}{l}\text { WHO biosafety } \\
\text { guidelines }\end{array}$ & $\begin{array}{l}\text { Current } \\
\text { MPHL }\end{array}$ & Comment \\
\hline Isolation ${ }^{\mathrm{a}}$ of laboratory & No & No & \\
\hline $\begin{array}{l}\text { Room sealable for } \\
\text { decontamination }\end{array}$ & No & No & \\
\hline \multirow{2}{*}{$\begin{array}{l}\text { Ventilation: } \\
\text { - Inward airflow } \\
\text { - Controlled ventilating system } \\
\text { - HEPA-filtered air exhaust }\end{array}$} & Desirable & No & \\
\hline & Desirable & Yes & \\
\hline Double-door entry & No & No & \\
\hline Airlock & No & No & \\
\hline Airlock with shower & No & No & \\
\hline Anteroom & No & No & \\
\hline Anteroom with shower & No & Yes & \\
\hline Effluent treatment & No & No & \\
\hline Autoclave: & No & No & \\
\hline $\begin{array}{l}\text { - On-site } \\
\text { - In the laboratory room } \\
\text { - Double-ended }\end{array}$ & Desirable & No & $\begin{array}{l}\text { Off-site; wastes } \\
\text { shipped }\end{array}$ \\
\hline Biological safety cabinet & No & No & \\
\hline \multirow{3}{*}{$\begin{array}{l}\text { Personal safety monitoring } \\
\text { capacity }^{b}\end{array}$} & No & No & \\
\hline & Desirable & Yes & Convinod hu Coron \\
\hline & No & No & seiviceu dy caluga \\
\hline
\end{tabular}


${ }^{a}$ Environmental and functional isolation from general traffic ${ }^{\text {b }}$ For example, window, closed-circuit television, two-way communication

Table 5: Safety survey; biosafety level 2: laboratory safety survey checklist adopted from the WHO biosafety manual, 3rd edition 


\section{Safety item}

\section{Biological safety cabinet (BSC)}

- Certification within last year

- BSC surface wiped down with appropriate disinfectant at the beginning and end of each procedure

- Front grill and exhaust filter unobstructed

- BSC compromised by room air or location

- BSC used when there is potential for creating aerosols

Laboratory

\section{Administrative Controls}

- Safety Policies, Procedures, and related forms

- Access limited and restricted to authorized personnel

- Entry limited to personnel advised of all potential hazards

- Biohazard signposted on laboratory door as appropriate

- All doors closed

\section{Decontamination}

- Decontaminant specific to the organism(s) in use

- All spills and accidents involving infectious materials reported to the laboratory supervisor

- Appropriate decontaminant used during spill clean-ups

- Work surfaces decontaminated before and after each procedure, daily and after spills

\section{Handling of contaminated waste and Hazardous chemicals}

- Infectious waste containers properly used

- Infectious waste not overfilled

- Infectious waste properly labeled and closed

\section{Personal protection}

- Laboratory personnel reminded of appropriate immunizations/tests for agents handled

- Gloves are worn when handling infectious material or contaminated equipment

- Face protection provided when working outside the BSC with infectious material

\section{Achieved Comment}

Yes

By UNHLS

Yes

Using $1 \%$ sodium hypochlorite

Yes

No

Yes

While loading the cartridges

Yes

Yes

Yes

Yes

Yes

Yes

Yes

Yes

Yes

To the biosafety officer

Yes

Yes

Yes

Always recommended 
- Hands washed after removing gloves, after working with infectious agents, before leaving the laboratory

- Antimicrobial agent available for immediate first aid

\section{Practices}

- BSC used when the potential for creating infectious aerosols/splashes exists

- Biosafety manual prepared and adopted

- Personnel read, review and follow the instructions on practices and procedures, including safety or operations manual (required for all personnel annually)

- Procedures performed to minimize aerosols/splashes

- Infectious specimens transported outside a BSC in approved containers following approved transport regulations

\section{Facility}

- Hand-washing sink available near laboratory exit

- Firefighting equipment
Yes

Yes

Yes

No

Immunized against hepatitis $B$ and tested monthly for COVID

Yes

Yes

Yes

Yes

Yes

Yes

Yes
Always recommended

No approved antiSARS-Cov-2

Use of face shields and goggles

Whenever loading the cartridge

Documented in the SOPS read

Potential step is done inside the BSC

Triple packaging used and transportation in cryovials

3- 4 meters away from the 
exit

$\mathrm{CO}_{2}$ extinguisher

and hose-reel

\section{Lab equipment and resources}

The installation of all the necessary equipment; four GX-VI-4 R2 Dx Module instrument with desktop computer and monitor, one GX-XVI-16 R2 Dx Module instrument with desktop computer and monitor, two barcode scanners, two printers, Uninterruptible Power Sources (APC and TRIPP-LITE), Power surge protectors, Batteries; SteriGARD ® $\mathbf{e}^{3}$ Class II Biosafety Cabinet; Refrigerator/Freezer SIBIR V $170 \mathrm{GE}$, Information, Communication, and Technology (ICT) gadgets (3 DELL Smart 42" computers, Tripp Lite Server and Racks) and two HP color laser Jet pro-MFP printers was successfully done.

A team of 8 Competent Superusers of GeneXpert from the Uganda National Tuberculosis Reference Laboratory (NTRL) was deployed to start testing with targeted capacity building at the Mutukula Land Point of Entry (POE).

The refrigerator installed has two compartments of temperature ranges of $2-8^{\circ} \mathrm{C}$ and $-20^{\circ} \mathrm{C}$. The $2-8^{\circ} \mathrm{C}$ is used for short term storage of samples while for long term storage the samples are placed in the freezer compartment. Samples are transported to the lab from the sample collection area in cryo - boxes while those for shipment to Uganda National Health Laboratory Services (UNHLS) are always packed in the cooler boxes supplemented with icepacks and transported within 5 hours.

The disinfectants selected had proven activity against enveloped viruses, including sodium hypochlorite (bleach; for example, 1000 parts per million [ppm] (0.1\%) for general surface disinfection and $10000 \mathrm{ppm}$ (1\%) for disinfection of spills; $70 \%$ ethanol or $80 \%$ isopropanol for hand, surfaces, and GeneXpert platform decontamination. The contact time for the bleach was set to 10 minutes.

\section{Onsite assay verification results}

The sensitivity, specificity, positive predictive value and negative predictive value were $100 \%$ for the Xpert ${ }^{\circledR}$ Xpress SARS-CoV-2 Assay at MPHL against the gold standard Conventional PCR test done at Makerere University Molecular Microbiology Laboratory (MML) as stated in Table 1.

\section{Laboratory commissioning}

The National COVID-19 Incident Commander, Chief Government Pathologist, Laboratory Director UNHLS, Minister of Health, Uganda CDC Director, WHO Country Representative to Uganda inspected the laboratory and thereafter commissioned it on the 15 May 2020. A team of officials from the Ministry of Health led by the Permanent Secretary noted that the border station required its specialized laboratory services to respond to the big COVID-19 threat presented by neighboring countries (20). She further noted that the immediate certification of the laboratory for COVID-19 testing would provide Polymerase Chain Reaction 
(PCR) testing to all people entering the country from Tanzania, to avoid scenarios of positive cases getting into contact with the community (20).

\section{Implementation of Quality Assurance Activities}

A Cepheid super user together with the National Cepheid Authorized support Provider trained the Technical team on how to conduct the Xpert ${ }^{\circledR}$ Xpress SARS CoV-2 Testing. Quality assurance activities involved the assay verification, GeneXpert machine maintenance, and results reporting using training materials from Cepheid [25]. Training and competence evaluation checklists were used to ascertain the proficiency reliably and reproducibly running the Xpert® Xpress SARS CoV-2 assay. For continuous quality improvement and preservation, the equipment and LIMS installation were validated and maintained as well as Lot testing and responding to feedback from Quality Audits, Customer Satisfaction Survey and EQA reports.

Initially, the SARS-CoV-2 testing of samples collected at Mutukula Land Point of Entry was limited to inhouse PCR done at the Uganda Virus Research Institute (Entebbe, Uganda) before the implementation of the Xpert ${ }^{\circledR}$ Xpress SARS-CoV-2 testing at Mutukula Port Health. By early July 2020, the Mutukula Xpert ${ }^{\circledR}$ Xpress SARS CoV-2 testing Laboratory had worked on over 11,000 samples with a regular reduction in the results turnaround time. The median results TAT before and after implementation of Xpert® Xpress SARS-CoV-2 testing at Mutukula Port Health Laboratory (MPHL) was compared using the Mann-Whitney test. The results turn-around time (TAT) has been defined as the duration between the sample shipment to results reception by the client. It was found that the median difference between the two TATs was statistically significant (Man-Whitney test) with Xpert ${ }^{\circledR}$ Xpress SARS CoV-2 testing having a median of 75 minutes (IQR: $60-75$ minutes) as compared to the median TAT of 1980 minutes (IQR: $1980-2880$ minutes) for the in-house PCR based assay (Fig 2).

The proportion of results released within the target TAT of 75 minutes at Mutukula improved over a month above the targeted percentage of 80 .

Mutukula Port Health Laboratory had a kappa statistic of 95\% agreement with Tororo COVID-19 Mobile Field-Testing Lab in the Inter-Laboratory comparison re-testing program. Xpert ${ }^{\circledR}$ Xpress SARS CoV-2 assay detected all the 10 and 8 for the panel positives and negatives respectively. However, one of the 2-panel presumptive positives was detected as a positive which led to the reduction in the kappa percentage agreement.

\section{The assessment for capacity and capability to conduct COVID-19 testing}

The overall score for the capacity and capability to conduct COVID-19 testing by Mutukula Port Health Laboratory was reported to be $90 \%$. This was above the limit of $80 \%$ that is required by any laboratory that implements or intends to conduct COVID-19 testing (Figure 7). 


\section{Discussion}

This Ugandan experience indicates that, with collective efforts and technical support from locally available expertise, it is achievable to set-up and optimally operate a safe BSL-2 Xpert $\circledast$ Xpress SARSCoV-2 testing facility with satisfactory quality performance in a resource-limited setting. Setting up an Xpert ${ }^{\circledR}$ Xpress SARS CoV- 2 implementation team that is acquainted with the international and national requirements for construction, equipment installation, Bio-risk management, Quality Assurance, COVID-19 diagnostics in addition to recruitment of experienced personnel in the use of GeneXpert Systems and outbreak rapid response before initial laboratory set-up is key to achieving the set start-up targets. Initial and continuous support from the Ministry of Health, its partners, multi-agencies at the port as well as open discussions on the possible limitations and finding out the alternative solutions ahead of time was also crucial.

Risk assessment was very crucial as it ensured a safe environment to perform the Xpert ${ }^{\circledR}$ Xpress SARS CoV-2 testing with appropriate mitigation measures in place thereby reducing the residual risk to an acceptable very low level.

The performance in the national verification of Xpert® Xpress SARS-CoV-2 assay (for the sensitivity, specificity, positive predictive value, and negative predictive value against the gold standard Conventional PCR) that was above $90 \%$ proved the suitability of the assay for its intended use in the population of truck drivers and returnees.

Understanding the satisfactory quality performance standards as well as planning the routes to achieving them upfront, including early monitoring of performance with corrective and preventative action projects and management commitment, have enabled MPHL to realize continuous quality improvement. This is evident with the exceptional growth of MPHL from a Zero to three (3) stars ranking within 60 days of operation. The baseline laboratory performance was assessed by internal auditors, employing standard assessment tools accessible at (26). From our findings, due to the initiation of onsite testing, the results turnaround time was reduced by 17 -fold which quickened on traffic flow at the border point as well as case detection and management. Even though the proportion of samples released on time is within the targeted ranges by July, root cause analyses should be done for those the few results that fall out of TAT.

The Inter-Laboratory comparison re-testing program agreement of $95 \%$ was within the acceptable range (our target of $80 \%$ and above). This was possible due to the strict proficiency procedures in the laboratory which require a mixture of senior and junior technologists at all times working on the bench to ensure effective competency transfer, training and competence assessments, and the effective use of standard operating procedures.

Generally, given the short time of operation the lab has been in existence, that performance as per the WHO assessment is very sufficient. The lowest score was from the core capacity; organization and management (67\%). From our understanding, this is a big challenge to many government-owned facilities for which the top management is always afar. 


\section{Conclusion}

Rapid diagnosis of COVID-19 using the Xpert® Xpress SARS-CoV-2 assay is feasible in resource-limited settings. Implementation of Xpert $\circledast$ Xpress SARS-CoV-2 testing for rapid diagnosis of COVID-19 at border points is critical in reducing the long TAT observed with Conventional Molecular based testing. The operationalization of the testing is largely dependent on the initial planning, human resource adequacy, and preparedness within the laboratory network. The key to the successful implementation of the testing is to involve an excellent network of agencies at the port. Challenges realized included the difference in approaches to COVID-19 response by Tanzania and Uganda, the attitude of truck-drivers on Infection Prevention and Control (IPC) measures, language barrier, and waste management issues.

\section{Abbreviations}

2019nCoV: 2019 Novel CoronaVirus

CDC: Center for Disease Control and Prevention

COVID-19: Coronavirus Disease 2019

PCR: Polymerase Chain Reaction

POC: Point of Care

RT: PCR - Real - Time Polymerase Chain Reaction

SARS - CoV - 2: Severe Acute Respiratory Syndrome Corona Virus-2

WHO: World Health Organization

\section{Declarations}

Ethics approval and consent to participate: The study didn't directly involve human subjects. The unique identifiers for any of the records corresponding to truck drivers were cloaked before being accessed by the study team. Permission to conduct the study was given by the Mutukula Port Health Laboratory Mana gement.

Consent for publication: Not applicable

Availability of data and materials: The datasets used and/or analysed (if any) during the current study are available from the corresponding author on reasonable request.

Competing interests: The authors declare that they have no competing interests.

Funding: None. 
Authors' contributions: AN designed the work, acquired and analyzed the data, drafted and substantively revised it. II acquired the data, analyzed, and interpreted, drafted and substantively revised the work. IS was a major contributor in writing the manuscript. BSB was a major contributor in writing the manuscript. AN was a major contributor in writing the manuscript.AK was a major contributor in writing the manuscript. DM was a major contributor in writing the manuscript. DT interpreted the data and was a major contributor in writing the manuscript. RKM interpreted the data and was a major contributor in writing the manuscript. FO was a major contributor in writing the manuscript. JK drafted the work, substantively revised it and was a major contributor in writing the manuscript. IA was a major contributor in writing the manuscript. EW was a major contributor in writing the manuscript. BM was a major contributor in writing the manuscript. LL was a major contributor in writing the manuscript. MO was a major contributor in writing the manuscript. SKK was a major contributor in writing the manuscript. CO was a major contributor in writing the manuscript. EK was a major contributor in writing the manuscript. PO was a major contributor in writing the manuscript. MLJ was a major contributor in writing the manuscript. SN was a major contributor in writing the manuscript. WS interpreted the data, drafted and substantively revised the work and was a major contributor in writing the manuscript. All authors read and approved the final manuscript.

Acknowledgements: We would like to acknowledge the staff members of Mutukula Port Health Laboratory for their support during the time this study was being implemented.

\section{References}

1. Huang C, Wang Y, Li X, Ren L, Zhao J, Hu Y, et al. Clinical features of patients infected with 2019 novel coronavirus in Wuhan, China. Lancet. 2020.

2. Chen N, Zhou M, Dong X, Qu J, Gong F, Han Y, et al. Epidemiological and clinical characteristics of 99 cases of 2019 novel coronavirus pneumonia in Wuhan, China: a descriptive study. Lancet. 2020.

3. Wang D, Hu B, Hu C, Zhu F, Liu X, Zhang J, et al. Clinical Characteristics of 138 Hospitalized Patients with 2019 Novel Coronavirus-Infected Pneumonia in Wuhan, China. JAMA - J Am Med Assoc. 2020.

4. Zarocostas J. What next for the coronavirus response? Lancet (London, England). 2020.

5. International Committee on Taxonomy of Virus. Naming the 2019 Coronavirus (2020). 2020; Available from: https://talk.ictvonline.org/

6. World Health Organization. Naming the coronavirus disease (COVID-19) and the virus that causes it. World Heal Organisation. 2020.

7. Singhal T. A Review of Coronavirus Disease-2019 (COVID-19). Indian J Pediatr. 2020;87(4):281-286; doi:10.1007/s12098-020-03263-6

8. https://www.euro.who.int/en/health-topics/health-emergencies/coronavirus-covid-19 accessed on $15^{\text {th }}$ August, 2020.

9. World Health Organisation Coronavirus disease 2019 (COVID-19) Situation Report - 90. Geneva: WHO. (2020). Available online at: www.who.int/emergencies/diseases/novel-coronavirus- 
2019/situation-reports (accessed April 20, 2020).

10. Worldometer COVID-19 Coronavirus Pandemic. Dover, Delaware: Worldometers.info. (2020). Available online at: www.worldometers.info/coronavirus/ (accessed August 20).

11. Cascella M, Rajnik M, Cuomo A, et al. Features, Evaluation and Treatment Coronavirus (COVID-19). In: StatPearls [Internet]. Treasure Island (FL): StatPearls Publishing; 2020 Jan. Available from: https://www.ncbi.nlm.nih.gov/books/NBK554776/

12. Lu R, Zhao X, Li J, Niu P, Yang B, Wu H, et al. Genomic characterisation and epidemiology of 2019 novel coronavirus: implications for virus origins and receptor binding. Lancet. 2020.

13. Ranjit Sah1, Nayanum Pokhrel, Zareena Fathah., et al. SARS-CoV-2 / COVID-19: Salient facts and strategies to combat ongoing pandemic. Journal of Pure and Applied Microbiology. 2020.

14. World Health Orgaization (WHO). COVID-19 strategy update. 14 August, 2020

15. Lan L, Xu D, Ye G, Xia C, Wang S, Li Y, et al. Positive RT-PCR Test Results in Patients Recovered from COVID-19. JAMA - Journal of the American Medical Association. 2020.

16. Corman VM, Landt O, Kaiser M, Molenkamp R, Meijer A, Chu DKW, et al. Detection of 2019 novel coronavirus (2019-nCoV) by real-time RT-PCR. Eurosurveillance. 2020.

17. Nalla AK, Casto AM, Huang MLW, Perchetti GA, Sampoleo R, Shrestha L, et al. Comparative Performance of SARS-CoV-2 Detection Assays using Seven Different Primer/Probe Sets and One Assay Kit. J Clin Microbiol. 2020

18. Lee PI, Hu YL, Chen PY, Huang YC, Hsueh PR. Are children less susceptible to COVID-19? J Microbiol Immunol Infect. 2020.

19. Hofmann H, Pyrc K, Van Der Hoek L, Geier M, Berkhout B, Pöhlmann S. Human coronavirus NL63 employs the severe acute respiratory syndrome coronavirus receptor for cellular entry. Proc Natl Acad Sci USA. 2005.

20. https://www.cepheid.com/en/systems/GeneXpert-Family-of-Systems/GeneXpert-System accessed on the 10th July, 2020.

21. BDA Reporter (8 November 2017). "Tanzania, Uganda one-stop border post to cut clearance time". The EastAfrican Quoting Business Daily Africa. Nairobi. Retrieved 8 November 2017.

22. https://reliefweb.int/sites/reliefweb.int/files/resources/Situation\%20Report\%20\%20Southern\%20and\%20Eastern\%20Africa\%20COVID-19\%20Digest\%20-\%2030\%20Apr\%202020.pdf accessed on 2 August, 2020.

23. https://en.wikipedia.org/wiki/COVID-19_pandemic_in_Uganda accessed on 10 August, 2020.

24. World Health Organization (WHO). Laboratory biosafety guidance related to coronavirus disease 2019 (COVID-19). Interim guidance. 12 ${ }^{\text {th }}$ February, 2020.

25. Xpert® Xpress SARS-CoV-2 Assay ENGLISH Package Insert 302-3787 Rev. A.fm 26. https://apps.who.int/iris/handle/10665/204423 Accessed on 10 August, 2020.

\section{Figures}


Patient with any of the following signs and symptoms: Fever, Cough, Tiredness, loss of taste or smell, Shortness of breath or Difficulty breathing, Muscle aches, Chills, Sore throat, Runny nose, Headache, and Chest pain.

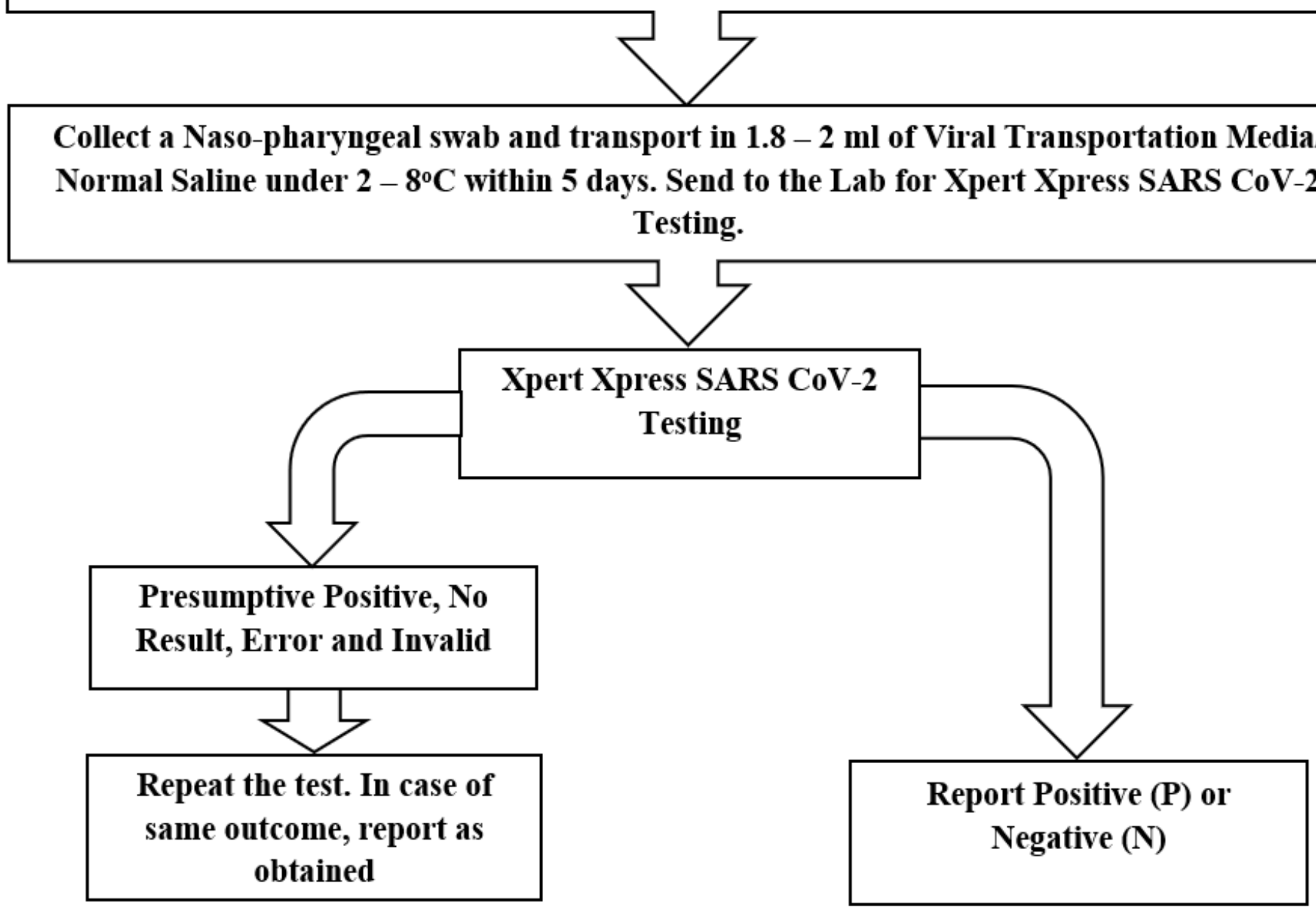

Figure 1

The Xpert® Xpress SARS-CoV-2 testing algorithm. 


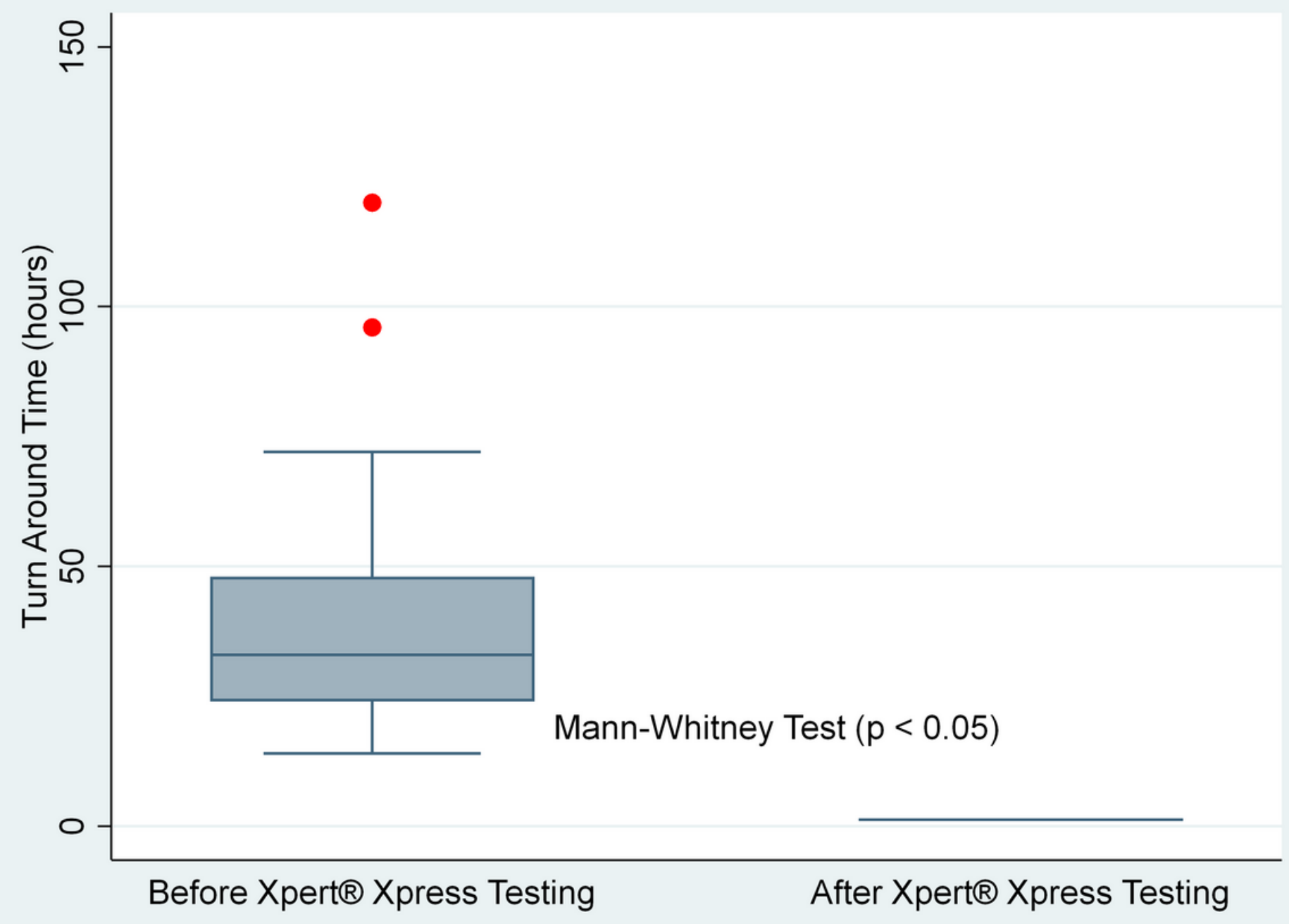

Figure 2

Comparison of the turnaround time between results of Xpert $\circledast$ Xpress SARS-CoV-2 assay and the Conventional PCR. 


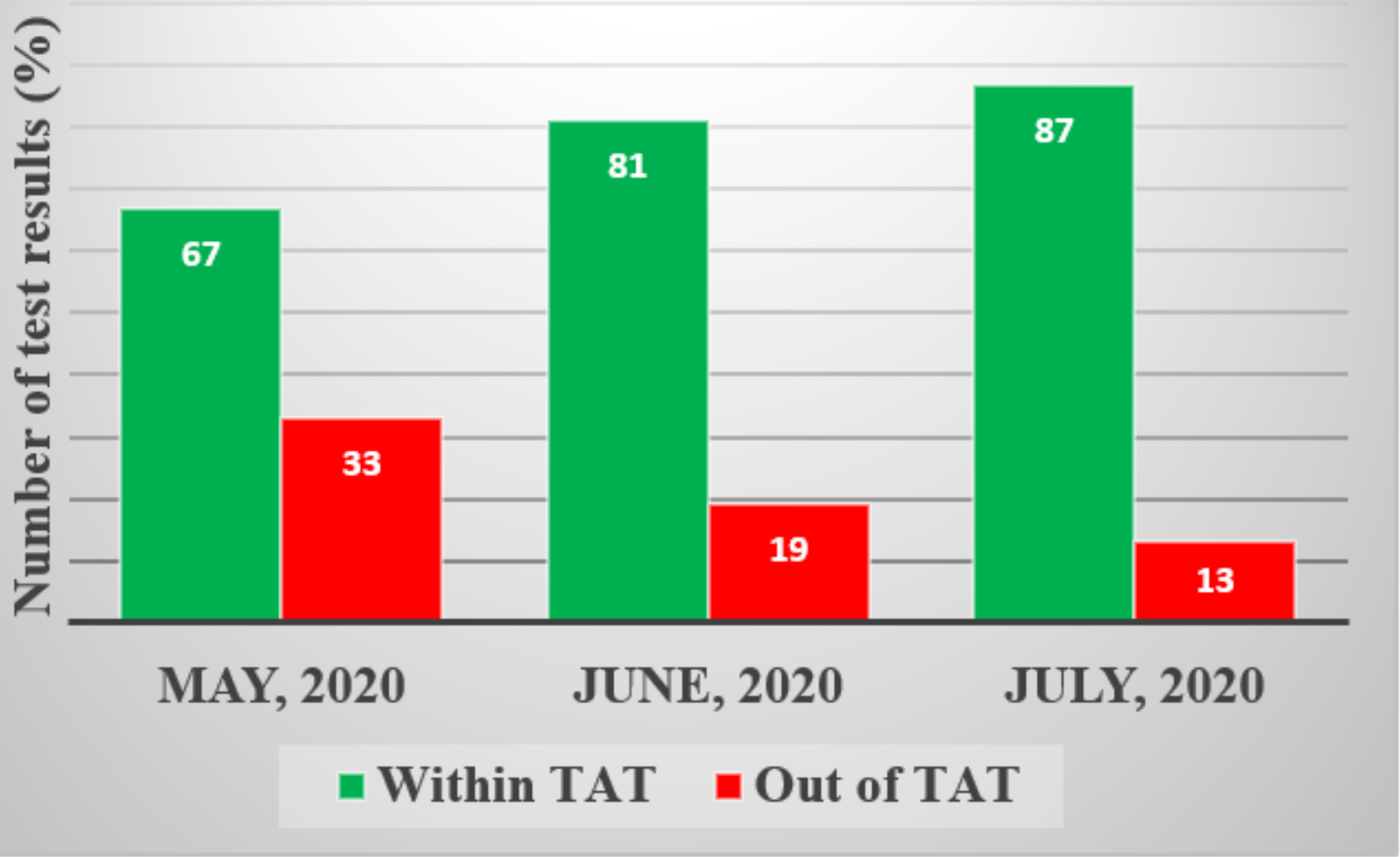

Figure 3

Proportion of results dispatched within and out of the target TAT (75 minutes).

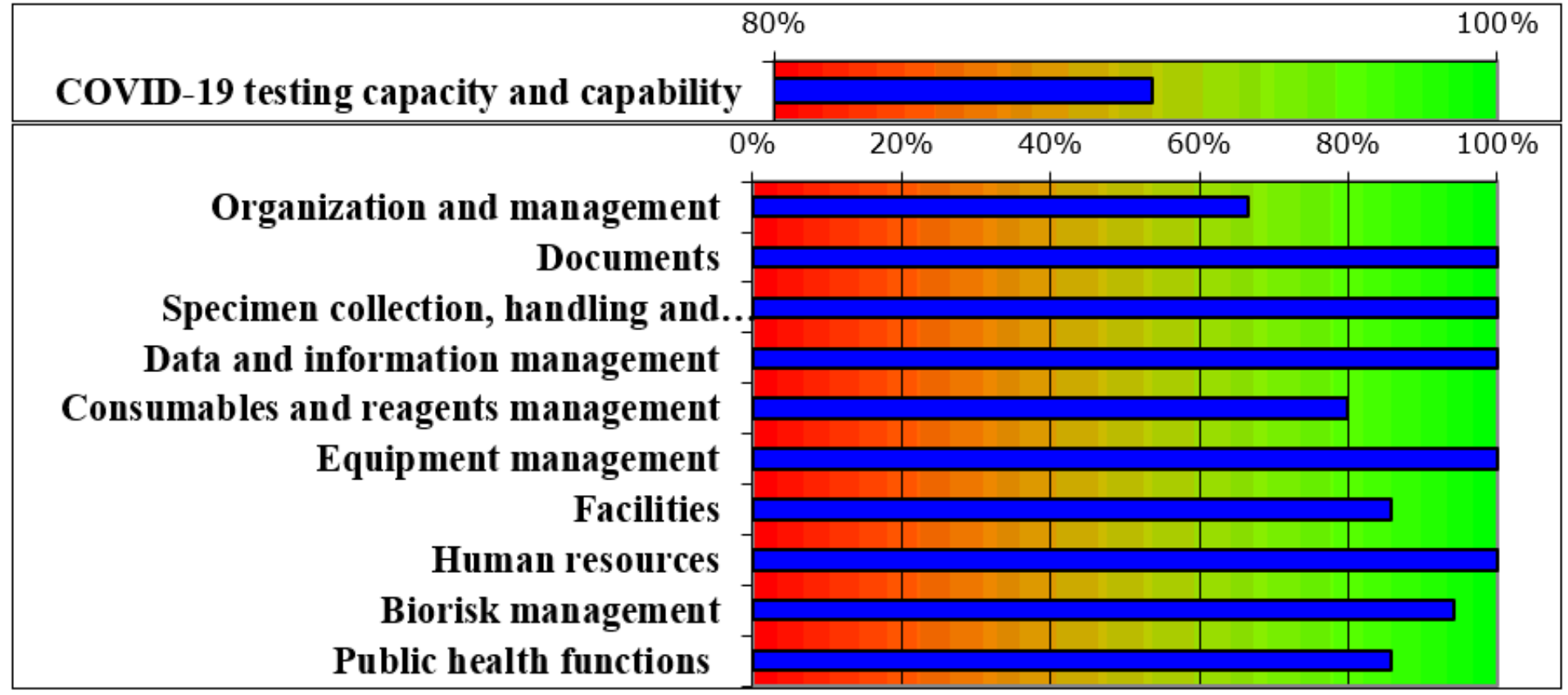

Figure 4

The scores for the COVID-19 testing core capacities and capabilities. 